\title{
Noninvasive intraocular pressure monitoring: current insights
}

This article was published in the following Dove Press journal:

Clinical Ophthalmology

30 July 2015

Number of times this article has been viewed

\author{
Stefan De Smedt \\ Department of Ophthalmology, \\ AZ St Maarten, Mechelen, Belgium
}

Correspondence: Stefan De Smedt Department of Ophthalmology, AZ St Maarten, Leopoldstraat 2, 2800 Mechelen, Belgium

$\mathrm{Tel}+3215419955$

Fax +32 I5 430798

Email dr.stefan.desmedt@gmail.com

Abstract: Glaucoma is the second leading cause of blindness worldwide and intraocular pressure (IOP) is currently its only modifiable risk factor. Peak IOP has for a long time been considered as a major contributor to glaucoma progression, but its effects may depend not only on its magnitude, but also on its time course. The IOP is nowadays considered to be a dynamic parameter with a circadian rhythm and spontaneous changes. The current practice of punctual measuring the IOP during office hours is therefore a suboptimal approach, which does not take into account the natural fluctuation of IOP. Because of its static nature a single IOP measurement in sitting position fails to document the true range of an individual's IOP, peak IOP, or variation throughout the day. Phasing means monitoring a patient's IOP during the daytime or over a 24-hour period. This can provide additional information in the management of glaucoma patients. This review focuses on the current insight of non-invasive IOP monitoring as a method of obtaining more complete IOP profiles. Invasive techniques using an implantable sensor are beyond the scope of this review.

Keywords: glaucoma, phasing, self-tonometry, contact lens sensor

\section{Introduction}

Glaucoma is a chronic optic neuropathy characterized by the excavation of the optic disc due to the atrophy of the retinal ganglion cells. A progression of such atrophy leads to further reduction of the visual field and eventually to the loss of sight at the end-stage of the disease. Glaucoma is the second leading cause of blindness worldwide and intraocular pressure (IOP) is currently its only modifiable risk factor. ${ }^{1}$ Peak IOP has for a long time been considered as a major contributor to glaucoma progression, but its effects may depend not only on its magnitude, but also on its time course. ${ }^{2-4}$ The IOP is nowadays considered to be a dynamic parameter with a circadian rhythm and spontaneous changes. ${ }^{5,6}$ The current practice of punctual measuring of the IOP during office hours is therefore a suboptimal approach, which does not take into account the natural fluctuation of IOP. Because of its static nature, a single IOP measurement in sitting position fails to document the true range of an individual's IOP, peak IOP, or variation throughout the day. ${ }^{7-9}$ Phasing means monitoring a patient's IOP during the daytime or over a 24 -hour period. This can provide additional information in the management of glaucoma patients. This review focuses on the current insight of noninvasive IOP monitoring as a method of obtaining more complete IOP profiles. Invasive techniques using an implantable sensor are beyond the scope of this review.

\section{Timing of diurnal fluctuation in IOP}

Diurnal fluctuations in IOP of up to $5 \mathrm{mmHg}$ have been reported in healthy subjects, and in glaucoma patients these variations are even higher. ${ }^{5,6}$ Initial studies suggested that the peak IOP occurred in the early morning, while other studies found a drop in IOP during 
the nocturnal period. ${ }^{10-12}$ However, if changes in body position that occur during sleep are taken into account by measuring the IOP in the physiologic positions (sitting while awake and supine while asleep), IOP is higher during the nocturnal/sleep period than during the diurnal period..$^{6,13,14}$ Other sleep-laboratory studies have confirmed that IOP in most glaucoma patients is at its highest value during the nocturnal/sleep period with the patient in the supine body position. ${ }^{8,15}$ Furthermore, like IOP, ocular perfusion pressure is believed to be a dynamic parameter with a circadian rhythm with dips at night or in the early morning. ${ }^{16}$ The timing of fluctuations in both IOP and ocular perfusion pressure may compromise the optic nerve head perfusion in susceptible individuals, worsening glaucoma in both functional and structural tests. ${ }^{4,17}$ Effects of the circadian IOP peaks may therefore depend on their time course as well as their magnitude. ${ }^{4}$ Animal-model research suggested that acceleration of the arterial blood pressure resulted in surges in IOP and this induced IOP variability may be more important in ocular hypertensive eyes. ${ }^{18,19}$

\section{Diurnal IOP fluctuation and glaucoma progression}

Variation in IOP has been increasingly considered to be important, with several studies suggesting that its fluctuations are an independent risk factor for glaucoma progression., ${ }^{4,20-27}$ Other studies, however, suggested that it is the absolute IOP itself rather than its fluctuation that had the most significant effect on glaucoma progression, but differences in study design, or failure in obtaining multiple IOP measurements on the same day, may explain these discrepancies. ${ }^{4,28,29}$ Apart from circadian variation, IOP can fluctuate randomly long-term, but its significance on glaucoma progression is unclear. ${ }^{23,30}$ Confusion regarding the definition of such long-term IOP fluctuations may contribute to this discrepancy. If the IOP measurements are taken at different times of the day on different visits, these fluctuations are not clearly distinguished from circadian variations. IOP measurements fluctuating over years on the other hand might represent true disease progression or change in therapy. ${ }^{31}$

\section{Benefits of IOP monitoring}

There are several benefits in documenting circadian IOP curves. Phasing allows detecting inherent IOP profiles that predispose to glaucoma development and progression, independently of absolute value of IOP. Patients with ocular hypertension who subsequently developed glaucoma had inherently different IOP profiles compared to non-converters. ${ }^{32}$ Particularly in patients with progressive visual field loss that is disproportionate to measured IOP, monitoring of the IOP provides additional information. ${ }^{7,33}$ It has been shown that analyzing IOP curves allows a more accurate detection of the IOP fluctuations and peak values, which occur outside office hours in 52\%-69\% of patients. ${ }^{7,34,35}$ Such 24-hour IOP monitoring led to immediate treatment change in over one-third of patients. ${ }^{7}$ In $11 \%-20 \%$ of the suspected cases of normal-tension glaucoma, IOP monitoring can register IOP values above $21 \mathrm{mmHg}$ during daytime or nighttime, and therefore it also allows identification of false-positive normal-tension glaucoma cases. ${ }^{36}$ Furthermore, the effect of various antiglaucoma drops on IOP over a 24-hour period can be compared. ${ }^{37-39}$ Identification of the chronobiology of a patient's IOP may help in selecting the appropriate IOP-lowering treatment with the right timing of application of drops for the individual patient. In addition to simple IOP reduction, this IOP "modulation" may help in reducing glaucoma progression. ${ }^{27}$ Another advantage is that the patient's understanding of glaucoma and adherence with glaucoma drops can be improved by visualizing 24-hour IOP profiles and the impact of therapy on them. It also allows identification of favorable and adverse behavioral and occupational patterns on IOP. ${ }^{9}$

\section{Strategies in IOP monitoring}

Phasing may be undertaken either only during clinic hours or covering a full 24-hour period. Monitoring of IOP limited to daytime pressure curves typically will represent only a portion of the 24-hour IOP pattern. It seems not to predict the nocturnal rhythm, suggesting that a full 24-hour circadian IOP profile should be evaluated in clinical practice. ${ }^{40}$ Although a retrospective study found no statistically significant increase in the mean peak IOP or mean IOP during the nighttime phasing period compared to the clinic or daytime phasing period, this study was prone to methodological weaknesses. ${ }^{33,41}$ Nevertheless, a major disadvantage of 24-hour monitoring compared to phasing during office hours is the need for sleep-laboratory settings which are costly and inconvenient for the patient. A 24-hour (nyctohemeral) IOP cycle is characterized by an acrophase, ie, the time period in this cycle during which the IOP curve peaks, and the bathyphase, which represents the part of the cycle during which the IOP curve is low.

\section{Phasing using Goldmann applanation tonometry}

There are several ways of documenting the 24-hour IOP cycle. Usually, 24-hour IOP rhythms are documented using 
Goldmann applanation tonometry (GAT). GAT is considered the "gold standard" for measuring IOP. The cornea is flattened over a defined area (3.06 $\mathrm{mm}$ in diameter) and the required applanation pressure serves to estimate IOP. This technique is based on the Imbert-Fick law and assumes that the eyeball is a perfect sphere and the cornea a perfectly thin, elastic, and flexible membrane. GAT is therefore influenced by several ocular factors, such as central corneal thickness, corneal biomechanical properties, and scleral rigidity. Apart from these biomechanical factors of bias, GAT also suffers from operator bias. ${ }^{42-44}$ It implies sitting in front of a slit lamp, which is far from the physiologic position during the nocturnal/sleep period. Even if the Perkins applanation or Tono-pen ${ }^{\circledR}$ (Reichert Technologies, Munich, Germany) are used in the supine position at night, awakening the patient remains necessary, potentially introducing stress-related artifacts, disturbing sleep organization, and ignoring dynamic changes related to daily-life physical activities. ${ }^{45}$ Reproducibility of inter-day IOP measurements with GAT has been reported to be only moderate at best in healthy volunteers and glaucoma patients. ${ }^{4,46-48}$

\section{Self-tonometry}

Another strategy in attempting to document round-the-clock IOP measurements is self-tonometry. Self-tonometry is an elegant alternative avoiding cumbersome hospitalization, and is a valuable adjunct to office measurements. In the practice of medicine today, patients with diabetes, asthma, and arterial hypertension participate actively in monitoring their diseases by frequent measurements of the blood glucose, peak flow, and blood pressure at home. Similarly, self-tonometry has the potential to empower the patient to take regular measurements of their IOP through the day and overnight in a familiar environment without stress, enhancing their compliance to therapy. Apart from discovering any fluctuations, self-tonometry may reduce the number of routine visits, but also expedite emergency evaluation of an acute angle closure attack. It opens up the perspective of the telemedicine application and can enlarge our understanding of glaucoma pathophysiology in ocular hypertension and normal-tension glaucoma. Several methods are available.

The Proview Eye Pressure Monitor (Bausch \& Lomb Incorporated, Bridgewater, NJ, USA) was invented by Fresco in $1997 .{ }^{49}$ It is a spring-compression device with a $3.06 \mathrm{~mm}$ diameter circular tip that is applied to the superonasal orbit over the upper eyelid while the eye is directed inferotemporally. As increasing pressure is applied to the eye, a visual sensation that has been variously described as like a solar eclipse or a dark circle surrounded by a bright halo is produced, and the measured IOP is read off the scale. Although the Proview tonometer is easy to use, there is no consensus on the effectiveness of the Proview tonometer. ${ }^{50}$ In a randomized prospective clinical trial involving glaucoma patients, the absolute mean difference between Proview Eye Pressure Monitor and GAT readings was 3.5 $\pm 2.9 \mathrm{mmHg} .{ }^{51}$ In patients with IOP less than $10 \mathrm{mmHg}$ or greater than $20 \mathrm{mmHg}$, this discrepancy with GAT was even higher $(6.6 \pm 3.6 \mathrm{mmHg})$ with an overestimation in lower IOP and overestimation in higher IOPs. ${ }^{51,52}$ The intraclass correlation coefficients between IOPs obtained with GAT and Proview were not strong (0.2), whereas for the GAT and the Tono-pen correlated fairly well (0.78) among glaucoma patients. ${ }^{53}$ In a prospective study, Proview detected a high IOP (defined as a Goldmann pressure of $>21 \mathrm{mmHg}$ by GAT) in only $18 \%$ (4/22) of patients. ${ }^{54}$ The Ocuton-S applanation self-tonometer is a hand-held electronic automatic applanation tonometer based on the same principles as the GAT, requiring anesthetic drops. This dependency on anesthetic drops and the fact that the device contacts the cornea in a "home" environment are of concern, because of the risks of corneal abrasion, ulceration, and infection. Furthermore, there is a lack of reproducibility compared to the results of the GAT-measurements. ${ }^{50}$

The Tiolat iCare tonometer is a hand-held unit which measures the deceleration of a magnetized probe in an electromagnetic field on the rebound from the cornea. It has the advantages of a noncontact unit, not requiring anesthetic drops. ${ }^{55}$ Its use as a self-tonometer has been reported and its readings correlate well with GAT. ${ }^{56}$ However, the iCare readings are influenced by the measuring position, with central IOP significantly greater than peripheral measurements by approximately 3-4 mmHg. ${ }^{57}$ When measurements are taken by patients on their own eyes in a home setting, these may not always be consistently obtained in the central position, hence questioning the accuracy and reproducibility of the IOP measurements. Self-tonometry techniques are therefore prone to technical difficulties for many older glaucoma patients. Last but not least, viable self-tonometry does not address the crucial issue of IOP behavior during undisturbed sleep. ${ }^{31}$

\section{Contact lens sensor}

Temporary IOP monitoring systems using a contact lens had been previously tried. Greene and Gilman embedded two strain gauges in a soft contact lens that could measure angular changes at the meridian angle of the corneoscleral junction secondary to IOP variations.$^{58}$ In order to detect small changes 
occurring at the meridian angle, the contact lenses needed to be custom molded for each eye, which made this prototype economically not viable. Twa et al integrated a piezo-resistive sensor tip of the dynamic contour tonometer in a hard contact lens, and their system provided reliable IOP measurements in a group of healthy volunteers for only up to 100 seconds. $^{59}$

\section{Concept of the contact lens sensor}

An alternative technique is a disposable contact lens sensor (CLS) (SENSIMED Triggerfish ${ }^{\circledR}$; Sensimed AG, Lausanne, Switzerland) that has been developed to register corneal curvature changes (Figure 1). ${ }^{58}$ The corneal curvature in human eyes correlates well with IOP, in which an IOP change of $1 \mathrm{mmHg}$ causes a change of central corneal radius of curvature of approximately $3 \mu \mathrm{m} .{ }^{60,61}$ In vitro studies using a sensor with an embedded micro-fabricated strain gauge on porcine eyes have demonstrated a very good correlation between the IOP variations and the changes in the corneal curvature measured in the corneoscleral area, where it is believed IOP changes induce maximum corneal deformation. ${ }^{62,63}$ Any ocular dimensional changes in the corneoscleral area are transmitted to the recorder expressed as an equivalent of the electric voltage (mV equivalents) (Figure 2). Recorded profiles are visualized graphically on a computer interface with approximately 300 data points acquired during a 30 -second period, every 5 minutes, resulting in a total of 288 measurements over a 24-hour period. As IOP fluctuates synchronically with heart rate, this 24-hour registration of IOP rhythm can be inspected for ocular pulsation, including systolic and diastolic peaks and ocular pulsation frequency (Figure 3). The noise could be significantly allowing the detection an artificially induced IOP change over a 10-minute interval in four human volunteers, correlating well with the expected GAT-values. ${ }^{64}$ IOP can be measured by GAT before and after CLS wear, but GAT

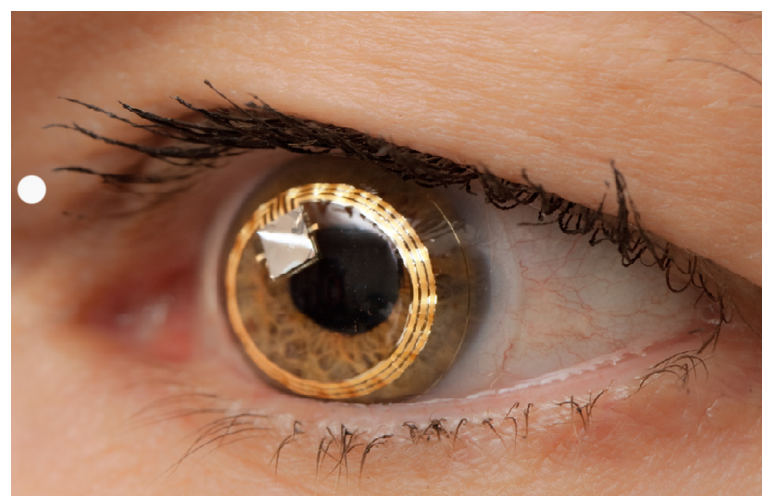

Figure I Contact lens sensor (SENSIMED Triggerfish ${ }^{\circledR}$ ) on the eye. Reproduced with permission from Sensimed AG (C) 2014.

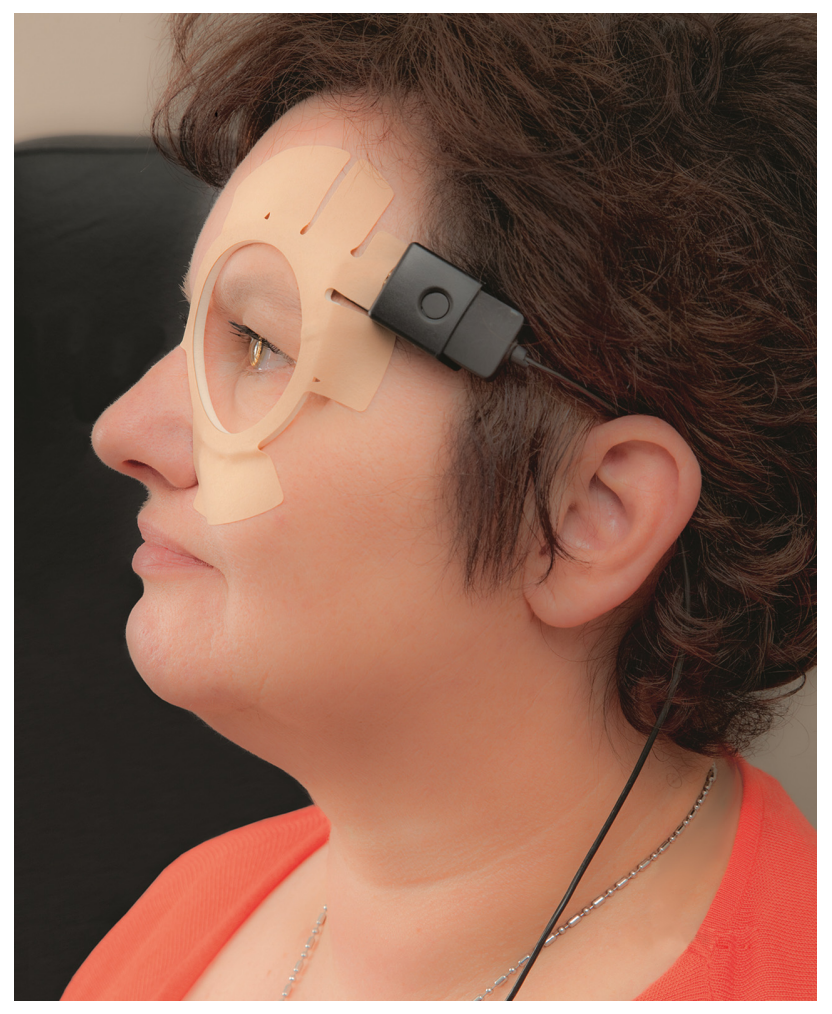

Figure 2 The sensor transmits the information to an antenna which is connected to a portable recorder. Reproduced with permission from Sensimed AG (c) 2014.

is not possible during the CLS wear, making simultaneous validation of the registered spikes difficult. ${ }^{65}$

\section{Functionality and tolerability of the CLS}

Studies in healthy subjects and glaucoma patients confirmed the functionality and tolerability of the CLS. ${ }^{66-68}$ The most common adverse effects were blurred vision, conjunctival hyperemia, and superficial punctate keratitis, all of which resolved spontaneously within 48 hours. Using the CLS, a moderate agreement between 24-hour IOP profiles in both healthy subjects and glaucoma patients was found when monitoring was repeated. ${ }^{69,70}$ The disposable CLS exists in three different base curves in order to ensure a good fit of the CLS, which is necessary for accurate measurements of small changes in the cornea and avoidance of movement artifacts of the strain gauges. Adapting a modified cosinor-rhythmometry method, this CLS allows accurate and reproducible registration of IOP rhythm with repeatable nocturnal acrophases seen in $62.9 \%$ of glaucoma patients. $^{71}$

\section{Clinical applications of the CLS}

Nocturnal acrophases showed a higher peak and a prolonged duration in patients with glaucoma $(70 \%)$ than in healthy subjects (33.3\%). ${ }^{40}$ A study evaluating the effect of selective 


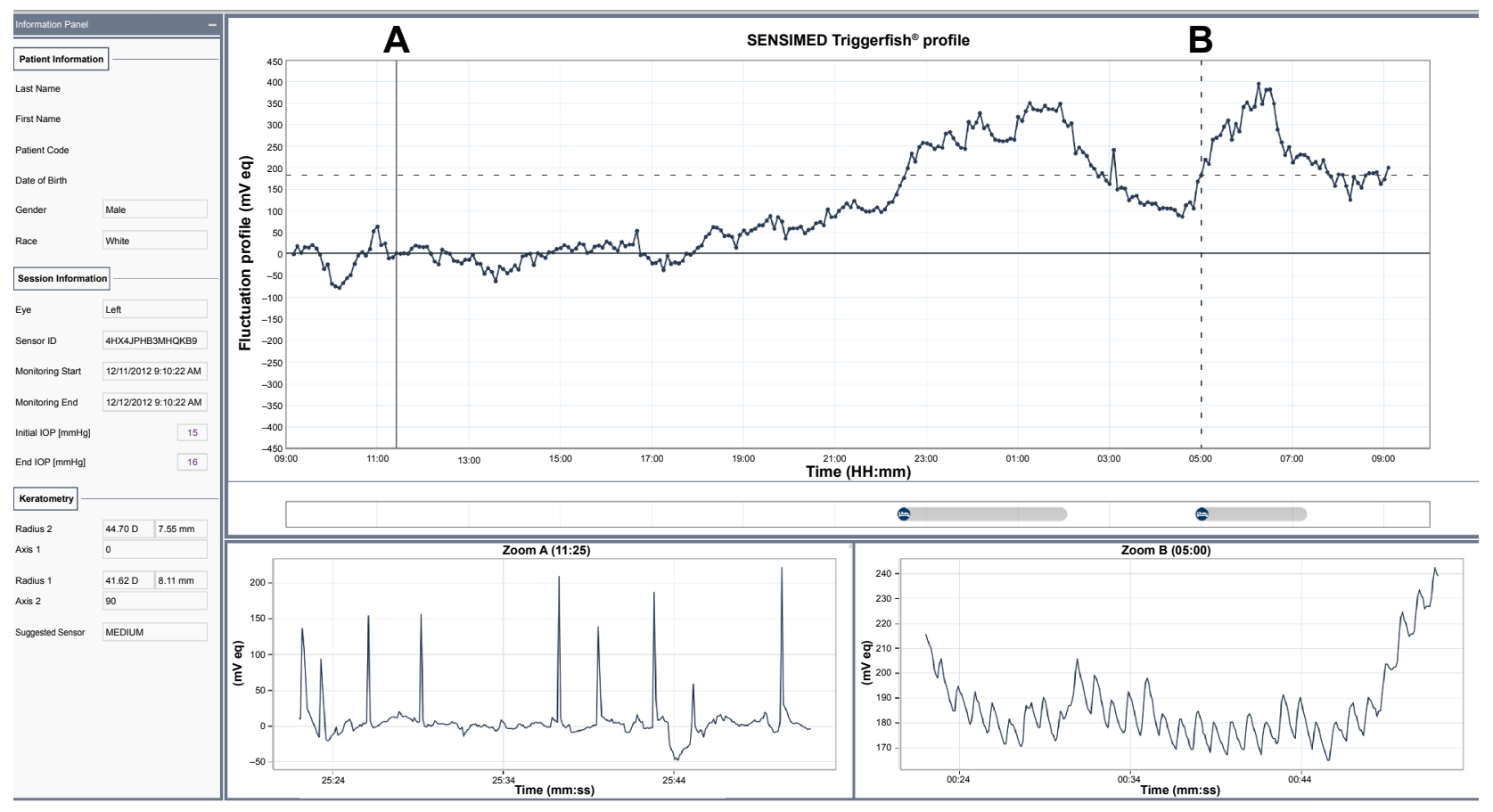

Figure 3 Registration signal over 24 hours (expressed in $\mathrm{mV}$ eq output of the sensor), with a close-up during the day (zoom A) and night (zoom B). Reproduced with permission from Sensimed AG (c) 2014.

Abbreviation: $\mathrm{mV}$ eq, millivolt equivalents.

laser trabeculoplasty demonstrated a reduction of the mean acrophase amplitude of the fitted cosinor function (global variability) by $24.6 \%$ after selective laser trabeculoplasty in the success group. ${ }^{72}$ The CLS was found to be sensitive to individual IOP rhythms and to differences in such rhythms induced by anti-glaucomatous drug therapy. ${ }^{73}$ Some studies suggested that the CLS is a more sensitive method than the noncontact tonometry in documenting characteristic acrophases and bathyphases of a 24-hour IOP rhythm in healthy participants. ${ }^{69}$ Others, however, found 24-hour GAT IOP measurements far superior in detecting a treatmentinduced significant IOP decrease than the CLS system. ${ }^{74}$ These authors were concerned that a trend for increasing measurement values along with increasing time of CLS wear during the 24-hour measurement period may mask some of the true IOP-related alterations induced by treatment or related to postural changes. ${ }^{74}$ Another study reported that an increased IOP induced by a ring pressed against the eye did not result in increased recording of the CLS, while GAT did detect the increased IOP values, suggesting that the relationship between IOP and corneal curvature also depends on thickness and elasticity of cornea and sclera, and variable corneal hydration. ${ }^{75}$ This discrepancy, however, could be due to improper use of the CLS, since pressing with a ring prevents the globe to expand freely and naturally, and hence prevents the capture of ocular dimensional changes in the corneoscleral area related to IOP. ${ }^{76}$

\section{Advantages and drawbacks of the CLS}

Currently, the CLS is the only commercially available device that has the potential to record the IOP-related profile over a prolonged period using a minimally invasive technique, regardless of the position of the patient and his activities, thus opening up new perspectives for the management of glaucoma. Furthermore, the CLS output also gives information on the effect of eye blinks and eye movements on IOP and documents the ocular pulsation continuously (Figure 3). One major drawback of the CLS is that its values are expressed in $\mathrm{mV}$ equivalents (instead of $\mathrm{mmHg}$ ), making the clinical interpretation challenging. Algorithms need to be developed to translate these units to a more clinically relevant form. With the current commercial price of around 500 Euros per eye per 24 hours, affordability of the technology is also another important issue, but this needs to be put into perspective of the high costs of running a sleep laboratory.

\section{Conclusion}

There is mounting evidence that IOP fluctuations play an important role in the development and progression of glaucoma. Despite numerous efforts, temporary monitoring of 
IOP over a 24-hour period in humans remains a technical challenge. Currently, the CLS is the only commercially available device that is promising in providing 24-hour information on IOP fluctuations. Further development of this technology will be a critical step in understanding and managing IOP variations in glaucoma.

\section{Acknowledgment}

The author thanks Sensimed AG for the illustrations used in this work.

\section{Disclosure}

The author reports no conflicts of interest in this work.

\section{References}

1. Resnikoff S, Pascolini D, Etya'ale D, et al. Global data on visual impairment in the year 2002. Bull World Health Organ. 2004;82(11): 844-851.

2. Zeimer RC, Wilensky JT, Gieser DK, Viana MA. Association between intraocular pressure peaks and progression of visual field loss. Ophthalmology. 1991;98(1):64-69.

3. Konstas AG, Quaranta L, Mikropoulos DG, et al. Peak intraocular pressure and glaucomatous progression in primary open-angle glaucoma. J Ocul Pharmacol Ther. 2012;28(1):26-32.

4. Mansouri K, Weinreb RN, Medeiros FA. Is 24-hour intraocular pressure monitoring necessary in glaucoma? Semin Ophthalmol. 2013;28(3):157-164.

5. Liu JH, Kripke DF, Twa MD, et al. Twenty-four-hour pattern of intraocular pressure in the aging population. Invest Ophthalmol Vis Sci. 1999;40:2912-2917.

6. Liu JH, Zhang X, Kripke DF, Weinreb RN. Twenty-four-hour intraocular pressure pattern associated with early glaucomatous changes. Invest Ophthalmol Vis Sci. 2003;44(4):1586-1590.

7. Barkana Y, Anis S, Liebmann J, Tello C, Ritch R. Clinical utility of intraocular pressure monitoring outside of normal office hours in patients with glaucoma. Arch Ophthalmol. 2006;124(6):793-797.

8. Mosaed S, Liu JH, Weinreb RN. Correlation between office and peak nocturnal intraocular pressures in healthy subjects and glaucoma patients. Am J Ophthalmol. 2005;139(2):320-324.

9. Mansouri K. The road ahead to continuous 24-hour intraocular pressure monitoring in glaucoma. J Ophthalmic Vis Res. 2014;9(2): 260-268.

10. Drance SM. The significance of the diurnal tension variations in normal and glaucomatous eyes. Arch Ophthalmol. 1960;64:494-501.

11. Kitazawa Y, Horie T. Diurnal variation of intraocular pressure in primary open-angle glaucoma. Am J Ophthalmol. 1975;79(4): 557-566.

12. Konstas AG, Mantziris DA, Cate EA, Stewart WC. Effect of timolol on the diurnal intraocular pressure in exfoliation and primary open-angle glaucoma. Arch Ophthalmol. 1997;115(8):975-979.

13. Liu JH, Kripke DF, Hoffman RE, et al. Nocturnal elevation of intraocular pressure in young adults. Invest Ophthalmol Vis Sci. 1998;39(13): 2707-2712.

14. Liu JH, Kripke DF, Hoffmann RE. Elevation of human intraocular pressure at night under moderate illumination. Invest Ophthalmol Vis Sci. 1999;40:2439-2442.

15. Hara T, Hara T, Tsuru T. Increase of peak intraocular pressure during sleep in reproduced diurnal changes by posture. Arch Ophthalmol. 2006;124(2):165-168.

16. Jürgens C, Grossjohann R, Tost FH. Relationship of systemic blood pressure with ocular perfusion pressure and intraocular pressure of glaucoma patients in telemedical home monitoring. Med Sci Monit. 2012;18(11):MT85-MT89.
17. Choi J, Kim KH, Jeong J, Cho HS, Lee CH, Kook MS. Circadian fluctuation of mean ocular perfusion pressure is a consistent risk factor for normal-tension glaucoma. Invest Ophthalmol Vis Sci. 2007;48(1): 104-111.

18. Li JC, Gupta VK, You Y, Ng KW, Graham SL. The dynamic response of intraocular pressure and ocular pulse amplitude to acute hemodynamic changes in normal and glaucomatous eyes. Invest Ophthalmol Vis Sci. 2013;54(10):6960-6967.

19. Vaajanen A, Mervaala E, Oksala O, Vapaatalo H. Is there a relationship between blood pressure and intraocular pressure? An experimental study in hypertensive rats. Curr Eye Res. 2008;33(4):325-332.

20. Mansouri K, Orguel S, Mermoud A, et al. Quality of diurnal intraocular pressure control in primary open-angle patients treated with latanoprost compared with surgically treated glaucoma patients: a prospective trial. Br J Ophthalmol. 2008;92(3):332-336.

21. Mansouri K, Medeiros FA, Weinreb RN. Letter to the editor: 24-hour versus daytime intraocular pressure phasing in the management of patients with treated glaucoma. Br J Ophthalmol. 2011;95(4): 594-595.

22. Asrani S, Zeimer R, Wilensky J, Gieser D, Vitale S, Lindenmuth K. Large diurnal fluctuations in intraocular pressure are an independent risk factor in patients with glaucoma. J Glaucoma. 2000;9(2): 134-142.

23. Nouri-Mahdavi K, Hoffmann D, Coleman AL, et al. Predictive factors for glaucomatous visual field progression in the Advanced Glaucoma Intervention Study. Ophthalmology. 2004;111(9):1627-1635.

24. Bergeå B, Bodin L, Svedbergh B. Impact of intraocular pressure regulation on visual fields in open-angle glaucoma. Ophthalmology. 1999; 106(5):997-1004; discussion 1004-1005.

25. Hong S, Seong GJ, Hong YJ. Long-term intraocular pressure fluctuation and progressive visual field deterioration in patients with glaucoma and low intraocular pressures after a triple procedure. Arch Ophthalmol. 2007;125(8):1010-1013.

26. Collaer N, Zeyen T, Caprioli J. Sequential office pressure measurements in the management of glaucoma. J Glaucoma. 2005;14(3):196-200.

27. Caprioli J, Varma R. Intraocular pressure: modulation as treatment for glaucoma. Am J Ophthalmol. 2011;152(3):340-344.

28. Jonas JB, Budde WM, Stroux A, Oberacher-Velten IM, Jünemann A. Diurnal intraocular pressure profiles and progression of chronic openangle glaucoma. Eye (Lond). 2007;21(7):948-951.

29. Ocular Hypertension Treatment Study Group; European Glaucoma Prevention Study Group, Gordon MO, et al. Validated prediction model for the development of primary open-angle glaucoma in individuals with ocular hypertension. Ophthalmology. 2007;114(1):10-19.

30. Bengtsson B, Leske M, Hyman L, Heijl A; Early Manifest Glaucoma Trial Group. Fluctuation of intraocular pressure and glaucoma progression in the early manifest glaucoma trial. Ophthalmology. 2007; 114:205-209.

31. Sit AJ. Continuous monitoring of intraocular pressure: rationale and progress toward a clinical device. J Glaucoma. 2009;18(4):272-279.

32. Grippo TM, Liu JH, Zebardast N, Arnold TB, Moore GH, Weinreb RN. Twenty-four-hour pattern of intraocular pressure in untreated patients with ocular hypertension. Invest Ophthalmol Vis Sci. 2013;54(1): $512-517$.

33. Moodie J, Wilde C, Rotchford AP, Vernon SA, King AJ. 24-Hour versus daytime intraocular pressure phasing in the management of patients with treated glaucoma. Br J Ophthalmol. 2010;94(8):999-1002.

34. Saccà SC, Rolando M, Marletta $\mathrm{A}$, Macrí $\mathrm{A}$, Cerqueti $\mathrm{P}$, Ciurlo G. Fluctuations of intraocular pressure during the day in open-angle glaucoma, normal-tension glaucoma and normal subjects. Ophthalmologica. 1998;212:115-119.

35. Hughes E, Spry P, Diamond J. 24-hour monitoring of intraocular pressure in glaucoma management: a retrospective review. J Glaucoma. 2003;12:232-236.

36. Renard E, Palombi K, Gronfier C, et al. Twenty-four hour (Nyctohemeral) rhythm of intraocular pressure and ocular perfusion pressure in normal-tension glaucoma. Invest Ophthalmol Vis Sci. 2010;51(2): 882-889. 
37. Quaranta L, Gandolfo F, Turano R, et al. Effects of topical hypotensive drugs on circadian IOP, blood pressure, and calculated diastolic ocular perfusion pressure in patients with glaucoma. Invest Ophthalmol Vis Sci. 2006;47(7):2917-2923.

38. Konstas AG, Holló G, Mikropoulos DG, et al. 24-hour efficacy of the bimatoprost-timolol fixed combination versus latanoprost as first choice therapy in subjects with high-pressure exfoliation syndrome and glaucoma. Br J Ophthalmol. 2013;97(7):857-861.

39. Seibold LK, Kahook MY. The diurnal and nocturnal effects of travoprost in normal-tension glaucoma. Clin Ophthalmol. 2014;8:2189-2193.

40. Agnifili L, Mastropasqua R, Frezzotti P, et al. Circadian intraocular pressure patterns in healthy subjects, primary open angle and normal tension glaucoma patients with a contact lens sensor. Acta Ophthalmol. 2015;93(1):e14-e21.

41. Schiefer U, Meisner C, Ziemssen F. 24-Hour intraocular pressure phasing remains an important tool in glaucoma diagnostics. Br JOphthalmol. 2011;95(4):594.

42. Ehlers N, Bramsen T, Sperling S. Applanation tonometry and central corneal thickness. Acta Ophthalmol (Copenh). 1975;53(1):34-43.

43. Liu J, Roberts CJ. Influence of corneal biomechanical properties on intraocular pressure measurement: quantitative analysis. J Cataract Refract Surg. 2005;31(1):146-155.

44. Whitacre MM, Stein R. Sources of error with use of Goldmann-type tonometers. Surv Ophthalmol. 1993;38(1):1-30.

45. Liu JH, Weinreb RN. Monitoring intraocular pressure for $24 \mathrm{~h}$. $\mathrm{Br} J$ Ophthalmol. 2011;95(5):599-600.

46. Wilensky JT, Gieser DK, Dietsche ML, Mori MT, Zeimer R. Individual variability in the diurnal intraocular pressure curve. Ophthalmology 1993;100(6):940-944.

47. Realini T, Weinreb RN, Wisniewski SR. Diurnal intraocular pressure patterns are not repeatable in the short term in healthy individuals. Ophthalmology. 2010;117(9):1700-1704.

48. Realini T, Weinreb RN, Wisniewski S. Short-term repeatability of diurnal intraocular pressure patterns in glaucomatous individuals. Ophthalmology. 2011;118(1):47-51.

49. Fresco BB. A new tonometer - the pressure phosphene tonometer: clinical comparison with Goldman tonometry. Ophthalmology. 1998; 105(11):2123-2126.

50. Liang SY, Lee GA, Shields D. Self-tonometry in glaucoma managementpast, present and future. Surv Ophthalmol. 2009;54(4):450-462.

51. Rai S, Moster MR, Kesen M, et al. Level of disagreement between Proview phosphene tonometer and Goldmann applanation tonometer intraocular pressure readings. J Glaucoma. 2005;14(2):120-123.

52. Tai MC, Chen PL, Wu JN, Lu DW. Clinical evaluation of the intraocular pressure in patients with glaucoma or ocular hypertension by a selfassessable tonometer. J Ocul Pharmacol Ther. 2005;21(1):55-61.

53. Li J, Herndon LW, Asrani SG, Stinnett S, Allingham RR. Clinical comparison of the Proview eye pressure monitor with the Goldmann applanation tonometer and the Tonopen. Arch Ophthalmol. 2004;122(8): 1117-1121.

54. Alvarez TL, Gollance SA, Thomas GA, et al. The Proview phosphene tonometer fails to measure ocular pressure accurately in clinical practice. Ophthalmology. 2004;111(6):1077-1085.

55. Kontiola AI. A new induction-based impact method for measuring intraocular pressure. Acta Ophthalmol Scand. 2000;78(2):142-145.

56. Rosentreter A, Jablonski KS, Mellein AC, Gaki S, Hueber A, Dietlein TS. A new rebound tonometer for home monitoring of intraocular pressure. Graefes Arch Clin Exp Ophthalmol. 2011;249(11):1713-1719.

57. Muttuvelu DV, Baggesen K, Ehlers N. Precision and accuracy of the ICare tonometer - Peripheral and central IOP measurements by rebound tonometry. Acta Ophthalmol. 2012;90(4):322-326.

58. Greene ME, Gilman BG. Intraocular pressure measurement with instrumented contact lenses. Invest Ophthalmol. 1974;13:299-302.
59. Twa MD, Roberts CJ, Karol HJ, Mahmoud AM, Weber PA, Small RH. Evaluation of a contact lens-embedded sensor for intraocular pressure measurement. J Glaucoma. 2010;19(6):382-390.

60. Hjortdal JO, Jensen PK. In vitro measurement of corneal strain, thickness, and curvature using digital image processing. Acta Ophthalmol Scand. 1995;73:5-11.

61. Lam AK, Douthwaite WA. The effect of an artificially elevated intraocular pressure on the central corneal curvature. Ophthalmic Physiol Opt. 1997; 17:18-24.

62. Leonardi M, Leuenberger P, Bertrand D, Bertsch A, Renaud P. First steps toward noninvasive intraocular pressure monitoring with a sensing contact lens. Invest Ophthalmol Vis Sci. 2004;45:3113-3117.

63. Leonardi M, Pitchon EM, Bertsch A, Renaud P, Mermoud A. Wireless contact lens sensor for intraocular pressure monitoring: assessment on enucleated pig eyes. Acta Ophthalmol. 2009;87:433-437.

64. Pitchon EM, Leonardi M, Renaud P, Mermoud A, Zografos L. First in vivo human monitoring of intraocular pressure fluctuation and ocular pulsation by wireless soft contact lens sensor. Poster presented at: $A R V O$. 27 April - 1 May 2008, Fort Lauderdale American Glaucoma Society, 18th Annual Meeting, March 2008, Washington. 2008.

65. Faschinger C, Mossböck G. [Continuous $24 \mathrm{~h}$ monitoring of changes in intraocular pressure with the wireless contact lens sensor Triggerfish ${ }^{\mathrm{TM}}$ First results in patients]. Ophthalmologe. 2010;107(10):918-922.

66. De Smedt S, Mermoud A, Schnyder C. 24-hour intraocular pressure fluctuation monitoring using an ocular telemetry Sensor: tolerability and functionality in healthy subjects. J Glaucoma. 2012;21(8):539-544.

67. Mansouri K, Shaarawy T. Continuous intraocular pressure monitoring with a wireless ocular telemetry sensor: initial clinical experience in patients with open angle glaucoma. Br J Ophthalmol. 2011;95(5): 627-629.

68. Lorenz K, Korb C, Herzog N, et al. Tolerability of 24-hour intraocular pressure monitoring of a pressure-sensitive contact lens. J Glaucoma. 2013;22(4):311-316.

69. Mottet B, Aptel F, Romanet JP, Hubanova R, Pépin JL, Chiquet C. 24-hour intraocular pressure rhythm in young healthy subjects evaluated with continuous monitoring using a contact lens sensor. JAMA Ophthalmol. 2013;131(12):1507-1516.

70. Mansouri K, Medeiros FA, Tafreshi A, Weinreb RN. Continuous 24-hour monitoring of intraocular pressure patterns with a contact lens sensor: safety, tolerability, and reproducibility in patients with glaucoma. Arch Ophthalmol. 2012;130(12):1534-1539.

71. Mansouri K, Liu JH, Weinreb RN, Tafreshi A, Medeiros FA. Analysis of continuous 24-hour intraocular pressure patterns in glaucoma. Invest Ophthalmol Vis Sci. 2012;53(13):8050-8056.

72. Lee JW, Fu L, Chan JC, Lai JS. Twenty-four-hour intraocular pressure related changes following adjuvant selective laser trabeculoplasty for normal tension glaucoma. Medicine (Baltimore). 2014;93(27):e238.

73. Pajic B, Pajic-Eggspuchler B, Haefliger I. Continuous IOP fluctuation recording in normal tension glaucoma patients. Curr Eye Res. 2011; 36(12):1129-1138.

74. Holló G1, Kóthy P, Vargha P. Evaluation of continuous 24-hour intraocular pressure monitoring for assessment of prostaglandin-induced pressure reduction in glaucoma. J Glaucoma. 2014;23(1):e6-e12.

75. Sunaric-Megevand G, Leuenberger P, Preußner PR. Assessment of the Triggerfish contact lens sensor for measurement of intraocular pressure variations. Acta Ophthalmol. 2014;92(5):414-415.

76. Leonardi M. Response to the letter to the editor entitled 'Assessment

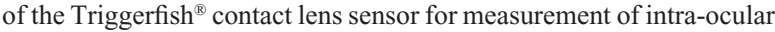
pressure variations'. Acta Ophthalmol. Epub 2014 Dec 7. 


\section{Publish your work in this journal}

Clinical Ophthalmology is an international, peer-reviewed journal covering all subspecialties within ophthalmology. Key topics include: Optometry; Visual science; Pharmacology and drug therapy in eye diseases; Basic Sciences; Primary and Secondary eye care; Patient Safety and Quality of Care Improvements. This journal is indexed on

Submit your manuscript here: http://www.dovepress.com/clinical-ophthalmology-journal
PubMed Central and CAS, and is the official journal of The Society of Clinical Ophthalmology (SCO). The manuscript management system is completely online and includes a very quick and fair peer-review system, which is all easy to use. Visit http://www.dovepress.com/ testimonials.php to read real quotes from published authors. 